\section{A teoria dos modelos em Miguel Reale e Karl Renner}

Rozangela Motiska Bertolo

Mestranda em Direito pela Universidade Federal do Rio Grande do Sul

SUMÁRIO

Introdução; I - A teoria dos modelos em Miguel Reale; II - As instituiçōes legais e sua função social em Karl Renner; III - As concepçōes examinadas sob o prisma da teoria dos modelos; Conclusão.

\section{Abstract}

The article develops the examination on the Miguel Reale and Karl Renner's scientific conceptions.

The author searches the juridical philosophic conception of the Theory of Models and its tridimensionality (fact, value and norm) as ele ments of juridical experience comprehension, that permeates the Miguel Reale's work.

Searches further more to identify the scientific legal theory based on the analisys of the Social Function of Legal Institutions elaborated by Karl Renner.

The work concludes that is based on the con ception of Models Theory that we can delineate an analisys of the studied works.

\section{Introdução}

Ao examinar as concepções científicas do direito de Miguel Reale e Karl Renner, buscou-se em suas obras identificar se, e em que aspectos, suas teorias apresentam relação ou pontos de contato ou podem ser examinadas sob um ângulo que permita uma unidade analítica.

Primeiramente, passa-se a examinar o pensamento de Miguel Reale ${ }^{1}$, sua concepção jusfilosófica da teoria dos modelos na sua ótica tridimensional, cuja formulação e desenvolvimento permeiam todas as suas obras.

Conforme aponta Luiz Fernando Coelho, destacam-se dois momentos na obra de Reale:
Tem-se nas obra de Reale a visão do
jurista, do filósofo e do cientista do direito ${ }^{5}$, verificando, também, o seu pensamento político através de seus escritos e de suas atividades.

Modelo do direito, termo proposto por Reale, na sua obra $O$ direito como Experiência tem seu conceito vinculado "à idéia de planificação lógica e à representação simbólica e antecipada dos resultados a serem alcançados por meio de uma seqüência ordenada de medidas e prescrições".

A idéia de modelo é a mesma da arquitetura, da matemática, da mecânica, no sentido de um projeto que condiciona uma construção.

Visualiza Reale duas espécies de modelos do direito ${ }^{7}$ e em ambos, idêntica tridimensionalidade:

1) Os de caráter teórico - os modelos dogmáticos ou hermenêuticos, como estruturas teoréticas elaboradas no âmbito d ciência do direito, que têm por finalidade dizer o que significam os modelos jurídicos. São estes modelos produto de doutrin e têm o papel de esclarecer os modelos jurídicos vigentes, abranger a superveniência de mudanças, identificando novos conteúdos, e promover e revogação quando ocorrer a dessuetude da norma.

2) Os modelos jurídicos, nos quais ocorre a previsão ou a prefiguração de uma "ordem de competências" ou "ordem de conduta" de uma estrutura normativa. São resultantes de atos de vontade que compreendem a opção do legislador, do juiz, da autonomia de vontade negocial.

A concepção de modelo jurídico de Reale não significa um "protótipo ideal", ma modelagens práticas, modelos práticos $\mathrm{d}$ experiência, "formas de viver concreto dos homens", ou seja: " estruturas normativas de fatos segundo valores instaurados em virtude de um ato concomitante de escolha prescrição". 8

O modelo jurídico é concebido pelo autor como uma estrutura dinâmica, sendo-lhe inerente o movimento, a direção ao fins a serem alcançados, destacando ser incompreensível a experiência jurídica sem se ter presente sua natureza dialética.9

Reale sustenta que uma teoria dos modelos jurídicos não se exaure no plano lógico- -formal ou pragmático, implicando o exame das estruturas normativas tanto no momento de sua configuração ou formação, estatuição, predeterminação normativa (racional) como também antes e depois desta fase, ou seja, desde quando o comportamento do indivíduo e sociedade vão concebendo e preservando formas de ser e de agir, ainda quando a força cogente apresenta-se difusa, resultando em parâmetros considerados legítimos e de interesse coletivo, público, identificados desde os romanos, até a sua persistência com o condicionamento histórico e de sua evolução e mutação.

Refletem-se no direito as várias estruturas normativas - modelos jurídicos -, compreendendo fatores que visam a "sua preservação e permanência", e fatores que buscam sua "reforma e substituição".

De um lado, os estudos filosóficos, sociológicos e antropológicos estão a demonstrar a mutabilidade dos modelos jurídicos; de outro, os imperativos de certeza e segurança jurídica atribuem-lhes configuração própria e autônoma. ${ }^{11}$

O exame do início e fim, da vida e morte dos modelos jurídicos, conduz ao exame da questão da vigência da norma na ocorrência da invalidade desta face ao conflito com normas hierarquicamente superiores ou a dessuetude em razão do contraste com os costumes e práticas em vigor consagrando-lhe o desuso.

A insuficiência ou superamento do modelo jurídico impõe sua substituiçāo.

Concebe Reale o direito como "processo dinâmico por excelência em que interagem e se implicam três elementos básicos: fato, valor e norma, que não se excluem... e nem se identificam, mas que se exigem (implicação) e são irredutíveis um ao outro ${ }^{12}$ (polaridade), sendo a norma o momentó de síntese do fato e valor.

Reale, na sua obra $O$ direito como Experiên cia, conclui que:

"As estruturas sociais compreendidas como estruturas fundamentais de uma sociedade apresentam-se, no que diz respeito à experiência jurídica, sob a forma de estruturas normativas ou sistema de modelos, 
sendo cada modelo dotado de especial estrutura de natureza tridimensional" ${ }^{13}$, no qual se realiza a dialética da complementariedade, a dialética aberta Reale.

Tem-se aqui o bojo das concepções de Reale que envolvem a sua Teoria Tridimensional do Direito e a sua concepção de Modelo Jurídico.

Para Reale, a compreensão da experiên cia jurídica em termos de modelos é de uma "estrutura normativa que ordena fatos segundo valores numa qualificação tipológica de comportamentos futuros que se ligam a determinadas conseqüências".

Representa a posição tridimensionalista, segundo Reale, o pensamento jusfilosófico contemporâneo de "repúdio a quaisquer imagens parciais ou setorizadas e a insuficiência da consideração isolada do que há de fático, de axiológico ou ideal, ou de normativo na vida do direito". ${ }^{15}$

Reale aponta várias obras nas quais a perspectiva tricotômica é identificada: em Legaz y Lacambra, Garcia Maynes, Carlos Cossio, caracterizando a compreensão tridimensional do direito como fenômeno universal.

Já no ponto de partida do legislador para elaborar a norma jurídica, há "um sentido axiológico, inseparável das circunstâncias histórico-sociais... . Entre fato, valor e norma existe, em suma, uma ligação de tal natureza que os três citados elementos se ordenam numa estrutura". 16

Assim, pois a "situação normada"17 é a expressão concreta numa totalidade significativa, correspondendo a uma estrutura complexa.

As enormes mudanças deste século destacam a necessidade da visão do direito como atividade ou como experiência, pondo o problema de sua compreensão integral. ${ }^{18}$

Somente tendo-se presente a complexidade desta estrutura jurídica, que não é estática, mas dinâmica, é possível a compreensão integral da experiência jurídica.

Sustenta Reale que "a teoria das fontes do Direito deve ficar adstrita ao momento genético das estruturas normativas as quais condicionam a existência de diversos mode- los jurídicos"119. Como se pode ver, o autor não pretende substituir a teoria das fontes pela teoria dos modelos, mas correlaciona las, apontando o caráter retrospectivo das fontes (a lei, o costume, a jurisprudência) sendo os modelos, prospectivos, "referem-se à norma enquanto se atualiza". 20

Reale reitera sua posição de que o historicismo jurídico hegeliano ou marxista oferece-nos uma visão parcial da problemática jurídica, exatamente porque não admite qualquer distinção entre ser e o dever ser, integrando-os numa unidade que exclui como ajurídicos ou acidentais os elementos de natureza não-racional. ${ }^{21}$

Somente seriam jurídicos quando convertidos racionalmente em norma.

Reconhece Reale, da contribuição de Hegel, o mérito de ter revelado que "uma atividade social, para tornar-se jurídica, não precisa necessariamente se converter em regra legal; isto é, em modelo legislativo"22 pondo em relevo o direito como atividade, não apenas como norma.

Todavia, como aponta Reale, Hegel situou "fora do âmbito dos sistemas jurídicos os valores existenciais que os condicionam, até o ponto se subsumi-los na unidade superior do Estado concebido como eticidade absoluta que integra e absorve a sociedade civil".

A dialética de Reale, desenvolvida fundamentalmente no seu $O$ Direito como Experiên cia e na sua Teoria Tridimensional do Direito, aparece como uma dialética aberta buscando estudar o direito estatal e o direito social de maneira correlacionada e complementar, segundo a dialética de complementariedade.

Reale entende ser essencial à plena compreensão do direito a análise: 1) da experiência juridica pré-categorial - expontânea (que continua a existir após as objetivações científicas, condicionando também o desenvolvimento das ciências que também refluem sobre ela) e,

2) de sua correlação com as instituições jurídicas - mundo racionalmente ordenado - em um sistema ou sistemas de regras. portanto científico - categorial e que entre as duas formas de experiência há uma recíproca e permanente influência. Os modelos normativos não se desvinculam do "mundo da vida" 24 , que condiciona sempre a experiência jurídica.

\section{II - As instituições legais e sua função social em Karl Renner}

A obra de Karl Renner ${ }^{25}$ apareceu esboçada nos Marxstudiem de 1904, sob o título A Funsão Social do Direito. Retomou-a o autor em 1929 sob o título: As instituigões do Direito Privado e sua Função Social.

Para Friedmann, in Legal Theory ${ }^{26}$, a ciência jurídica apresenta três estágios: o primeiro referente à formação do direito; o segundo, à sua formulação como norma, e o terceiro, à função social exercida pela norma.

É nesta última fase que Renner concentra seu trabalho. A teoria de Renner é a de que o direito, o quadro das instituições jurídicas, tem. uma certa invariabilidade natu$\mathrm{ral}^{27}$

Renner pressupõe as instituições estáticas, estáveis, neutras ${ }^{28}$, colocando toda a dinâmica de sua evolução na função social exercida pelas instituições, que situa fora do âmbito do direito:

Como explicar isto - a permanência da norma estável e a produção de efeitos e funções diferentes e sua profunda transformação com o passar do tempo?

Para o entendimento das concepções de Renner, há que se ter presente seu pensamento vinculado à escola marxista e positivista do pensamento jurídico.

Como todo positivista consistente, parece não admitir que o conteúdo das normas contidas em uma instituição jurídica venha a sofrer influência de suas funções como resultado de sua aplicação.

O entendimento do autor é de que o desenvolvimento da produtividade, o progresso técnico da humanidade são obtidos under the eye of the law, but not means of the lawer.
A legislação não é vista por Renner como autora de mudanças sociais, comprende-a o autor como reação às mudanças que têm lugar no âmago da sociedade ${ }^{30}$

Coerente com esta linha de pensamento, o autor condena o decretismo, entendendo que transform society by decree ou a idolatry of the decree ${ }^{31}$ é equivocada e uma superestimação de seus efeitos.

Renner identifica que as complexas relações envolvendo as instituições jurídicas e as relações de produção e consumo não se enquadram adequadamente na simplificada imagem arquitetônica de infra-estrutura e superestrutura.

Trata-se, segundo Renner, de um processo dialético em que as instituições são agrupadas e reagrupadas pela sociedade produzindo a transformação funcional de uma norma (instituição) que permanece imutável.

O Kahn-Freund ressalta a figura de uma criança que manipula blocos construindo ora uma mansão, ora uma fábrica, ora um trem, correspondendo os blocos às instituições pressupostas imutáveis e as "construções", à função social que sofre mudanças e evoluções. ${ }^{32}$

Renner concebe, pois, a norma como estática ${ }^{33}$ e a função social como dinâmica.

Renner denomina função econômica o resultado de muitas categorias jurídicas submetidas a um processo econômico.

Neste sentido, compreende as instituições jurídicas como instrumentos usados pela sociedade para realizar este processo, considerando-as engrenagens dos mecanismos de produção, consumo e distribuição do produto social.

Estas instituições realizam uma função social que Renner situa no campo da sociologia do direito.

Renner parte da pressuposição da estabilidade e relativa imutabilidade de instituições legais, tais como a propriedade, o contrato e concentra seu trabalho especialmente no exame da função social da primeira, que, em 1750 ou em 1900 e que, todavia, produz 
diferentes efeitos, às vezes quase opostos, nos aspectos econômicos e social.

Renner aponta que o fim último da sociedade, e por consequiência da função social das instituições jurídicas, é a manutenção da espécie, o que requer que a sociedade se organize em:

1) uma ordem de trabalho - order of la bour ${ }^{34}$ - que compreende a força necessária à produção e reprodução de mercadorias.

2) uma ordem de poder - order of power ${ }^{35}$ - com a função de comando para manter a organização em funcionamento.

3) uma ordem de bens ou coisas (mercadorias) - order of goods ${ }^{36}$ - representada pela detenção de coisas móveis ou imóveis onde estão incluídas as necessidades de consumo.

Renner concentra seu trabalho fundamentalmente no exame da função social da propriedade, sua evolução e mudanças na história do capitalismo.

Destaca o autor a definição de propriedade como concebida no direito continental europeu de fins do século XIX, especialmente em seus códigos, como o poder de gozar e dispor de alguma coisa da maneira mais absoluta. ${ }^{37}$

A utilização do bem pelo proprietário, seja para produção ou consumo, considera matéria fora do interesse do direito.

Para Renner, o direito atua no distúrbio da propriedade, na turbação, na aquisição, na perda. O uso normal da propriedade caracteriza como de interesse do economista, do sociólogo, não do jurista. ${ }^{38}$

Renner inicia o exame da transformação da função social da instituição jurídica da propriedade, na época da produção utilitária, ou seja, quando os produtores de bens eram camponeses e artesões, proprietários dos meios de produção vendendo diretamente os produtos ao consumidor. A casa continha o local de trabalho, as ferramentas, a moradia, portanto uma propriedade agrícola auto-suficiente, que tinha como finalidade manter o meio de vida do proprietário e de sua família - que era ao mesmo tempo unidade de produção e de consumo.
Nesta fase, coincide a propriedade legal e econômica, enfeixando o proprietário funções que mais tarde foram separadas.

Com o evoluir da história, estabelece-se o comerciante entre o produtor e o consumidor e com a industrialização adquire importância o contrato de work and labour. ${ }^{39}$

A propriedade, neste contexto, cumpria função de providenciar uma ordem de bens ou coisas e, em parte, uma ordem de poder. A propriedade familiar deixa de ser unidade de trabalho e de consumo.

A revolução francesa representou a ruptura com as instituições feudais, especialmente a extinção da nobreza e a adoção de uma concepção de propriedade decorrente da recepção do conceito romano.

A ordem de trabalho passou a exigir regramentos específicos, constituindo instituições complementares representadas primeiramente pelas corporações e depois pelo livre emprego.

Passam a haver sucessivas transformações na função social da instituição jurídica da propriedade.

Esta não provê mais a ordem de produção, o produtor passa a mero detentor dos meios de produção e do produto final, mas estes não são mais de sua propriedade.

Muda, também, a instituição jurídica da propriedade no que se refere ao consumo, a terra, a habitação, os meios de produção passaram a ser objeto de contratos de aluguel, arrendamento, que têm o papel de instituiçōes jurídicas complementares.

A pessoa do proprietário combinava em si funções que foram separadas, isto é, produzia ou adquiria matéria-prima, transformava-a no produto final e o vendia ao consumidor. ${ }^{41}$

Também o direito de família e o direito de sucessão cumpriam a função social de salvaguardar o processo de produção e reprodução de bens.

Aponta o trabalho de Renner que a instituição jurídica da propriedade permanece a mesma de sua concepcão inicial, mas tornou-se a chave exclusiva do domínio na sociedade capitalista.
A unidade da propriedade foi quebrada com a especialização em várias funções, deixando inclusive de representar o real controle sobre o bem. Ilustra este fato o exemplo de Renner ${ }^{42}$ de que a propriedade completamente hipotecada tem sua função econômica não com o proprietário legal, mas com o detentor da hipoteca. ${ }^{43}$

$\mathrm{Na}$ sociedade anônima, o domínio é do proprietário pleno, mas é o acionista controlador o detentor da função econômica, representando este exemplo a forma crescente de divórcio entre propriedade e domí nio econômico, propriedade e controle. ${ }^{44}$

Vê-se que os institutos complementares passam a exercer o domínio da sociedade, a ordem de poder, muitas vezes tornando o instituto da propriedade vazio de conteúdo, an empty legal form ${ }^{45}$.

Do proprietário de bens corpóreos passa-se ao proprietário do capital industrial.

O poder de comando, no período feudal, era atributo do proprietário da terra.

$\mathrm{Na}$ fase industrial, este "novo" poder de comando passa ao detentor de capital.

Multiplicam-se as instituições complementares da propriedade (contrato de servi ço, de empréstimo, de arrendamento, hipoteca, etc.) que passaram a exercer suas principais funções.

A posse física foi "purificada" através da detenção de certificados de depósito, war rants e outros documentos e títulos. ${ }^{46}$

O papel das sociedades anônimas, das estruturas modernas com as bolding e subsidiárias reforçam as teses de Renner.

Renner tomou o instituto jurídico da propriedade como base para a investigação da extensão em que a um instituto ou instituição jurídica corresponde uma função social.

III - As Concepções Examinadas sob ótica da Teoria dos Modelos

O agrupamento das normas positivas de forma sistemática em instituições legais bem como suas respectivas conceituações (propriedade, obrigações, aluguel, arrenda- mento, penhor) consistiu a grande contribuição do pensamento romano para a civilização. ${ }^{47}$

Jhering, conforme O. Kahn-Freund ${ }^{48}$, ressaltou o sucesso dos romanos em "retirar" de uma multidão de normas legais construir um "alfabeto" de conceitos legais os quais são pré-condições e ferramentas indispensáveis ao pensamento científico do direito.

É o que podemos chamar de definição das estruturas jurídicas fundamentais, das instituições jurídicas básicas ou, como pretende Reale, a prefiguração dos modelos jurídicos.

Pode-se tomar as expressões "instituições jurídicas" e "modelos jurídicos" como equivalentes, face a ambas significarem um conjunto, um compósito de normas ou estruturas normativas fundamentais da sociedade que constituem os institutos ou instituições juridicas ou os modelos jurídicos.

Ajusta-se à concepção de modelos de Reale o conceito de instituições identificados pelos romanos.

Isto permitirá uma unidade analítica no exame das concepções científicas do direito de ambos os autores que ora se estuda.

Modelo em Reale compreende a estrutura normativa tanto na sua configuração normativa, racional, positivada, quanto nas suas fases anteriores - formas de ser e de agir ainda difusas - e, posteriores, compreendendo sua evolução e mutação.

Reale abrange o agrupamento das estruturas normativas, dos modelos e, portanto, das instituições jurídicas em três fases:

1) numa fase anterior de concepção de formas de ser e de agir cuja forma cogente é ainda difusa e cujos parâmentros são também difusos;

2) numa segunda fase de configuração das normas que poderíamos chamar de positivação do direito, e;

3) numa fase posterior que envolve sua evolução e mutação e muitas vezes o desaparecimento de modelos jurídicos.

Para Reale, várias estruturas normativa constituem os modelos que compreendem as estruturas juridicas fundamentais, que 
autor ressalta serem formas de viver concreto dos homens e modelagens práticas experiência, cuja estrutura é essencialmente dinâmica, como já referimos anteriormente.

Reale compreende nos modelos normati-

vos fatores de preservação e permanência como de reforma e substituição e, neste sentido, aborda tanto a vida como a mort dos modelos quando o conflito de normas, sua dessuetude ou seu superamento impõem sua substituição.

A construção jusfilosófica do direito de Reale assenta-se no repúdio às imagens parciais e na compreensão do direito como processo dinâmico de implicação e polari dade de fato, valor e norma, do qual resutam estruturas jurídicas fundamentais $\mathrm{d}$ sociedade subsumidas em estruturas normativas ou sistemas de modelos concebido dentro de uma dialética aberta e de complementariedade.

A dinâmica deste século, que pode ser identificada e definida pela expressão $m u$ danşa ressalta a necessidade da compreensão integral do direito, nomeadamente como atividade e como experiência.

Neste contexto, Reale concebe os modelos como prospectivos, ou seja, de norma enquanto se atualizam, atribuindo às fonte o caráter retrospectivo.

Para Reale, é essencial à compreensão do direito o exame da experiência pré-categorial (espontânea) e a correlação com as instituições jurídicas ou sistema de regras (científica, categorial) e entre ambas permanente influência.

A concepção de modelo de Reale apresenta-se vinculada ao mundo da vida que condiciona a experiência jurídica, portanto não apenas produto racional do legislador, mas processo orgânico de constante evolução, permitindo a permanente renovação da ciência jurídica.

Reale estabelece sua construção jusfilosófica através de sua dialética aberta do dire to como experiência, concretizada nos modelos jurídicos dinâmicos e prospectivos que se complementam e se integram conten do as suas próprias possibilidades de mudança e evolução.
Compara Reale, como já se referiu na primeira parte deste trabalho, os modelos urídicos como modelagens práticas da experiência, com formas de viver concreto dos homens, com a prefiguração de ordens de conduta em estruturas normativas que resultam de atos de vontade do legislador, do juiz e da autonomia da vontade negocial.

Já Renner, ao desenvolver seu trabalho obre a função social das instituições juri dicas, cujo estudo representou, sem sombra de dúvida, um marco significativo no que e refere ao exame da função social exercida pelas normas, mais especificamente pelas instituições jurídicas, estabeleceu, na base de seu trabalho, a concepção de ciência do direito influenciada pela visão positivista de pureza normativa do positivismo científico ${ }^{49}$, ou seja, de que para a norma é indiferente a função que exerce, pressupondo as instituições jurídicas, além de estáveis e estáticas ${ }^{50}$, como neutras, isto é, "nem feudais, nem capitalistas, nem socialistas" ${ }^{\prime 51}$.

Renner conceitua a instituição legal como um compósito de normas, um todo de imperativos escritos ou impressos ${ }^{52}$

Para Renner, a transformação da função social das instituições jurídicas não significa a transformação das próprias instituições em parte do direito positivo ${ }^{53}$.

Todavia, Renner nem de longe desconhece a dinâmica da função social, simplesmente em decorrência e coerentemente com sua concepção de ciência do direito coloca esta dinâmica fora do âmbito do direito, isto é no campo da sociologia, da ciência política da economia, afirmando, reiteradas vezes, não presentarem matéria do interesse do jurista.

A visão de Renner, estritamente positivista, levou-o a ver a função social das institu ções jurídicas como fenômeno ajurídico ${ }^{54}$

A visão de Renner das instituições jurídicas se dá sob a ótica da dialética marxista que não admite a influência ou a interinfluência da superestrutura sobre a infra-esrutura.

Entretanto, o autor salienta que a metáfora arquitetônica de Marx é simplista para compreender a complexidade das relações entre direito e economia 55
A dialética marxista em Renner apresenta como jurídicas as relaçóes econômicas e sociais somente a partir do momento em que se convertem em normas de forma racional e objetiva, disto resulta num sistema fechado, numa visão parcial de problemática jurídica, típica da passagem do século XIX para o século $\mathrm{XX}^{56}$

O pensamento de Renner como cientista do direito, vinculado a uma visão de norma como estática e imutável, opõe-se à de Jhering, como também ao realismo americano, à escola do direito livre e às concepções contemporâneas que propugnam a interpretação das normas de acordo com seus propósitos sociais, uma vez que o trabalho de Renner parece indicar que o autor não admite que a norma, enquanto jurídica, possa ser influenciada por suas funções ou pelo próprio resultado de sua aplicação.

Observe-se que Renner afirma que a transformação da função social ocorre como a grama que cresce $^{57}$, não podendo esta transformação ser identificada num dado momento estanque, mas somente pode ser observada com o seu desenvolvimento gradativo. Com esta observação, o autor parece admitir, considerando a figura utilizada isoladamente, que a mudança da função social ocorre modificando a própria "grama", isto é, uma mudança gradual e im erceptível da própria instituição jurídica.

Advirta-se que a leitura desta imagem utilizada pelo autor, tendo em conta suas inúmeras advertências buscando separar instituições jurídicas - como estruturas normativas - da função social exercida pelas mesmas, leva a crer que este se referia exclusivamente à mudança das funções sociais especificamente e, portanto, fora do âmbito da ciência do direito e não às próprias estruturas normativas representadas pelas instituiçōes jurídicas.

Diferem basicamente os autores e isto se explica tanto pelas diferentes épocas em que foram escritos os trabalhos como pelas correntes de pensamento a que se filiam e, fundamentalmente, pela própria concepção de instituição e modelo jurídico com que trabalham.
Renner tem como jurídico exclusivamene norma, as estruturas normativas, as instituições jurídicas, não admitindo como jurídica a função social exercida por estas, considerando-a fora do mundo jurídico e não do interesse do jurista.

Esta visão dialeticamente fechada que Renner tem das instituições jurídicas o leva a situar as mudanças funcionais e suas interinfluências fora do âmbito do direito.

Neste ponto, divergem substancialmente os autores examinados.

Cabe ressaltar que Renner não desconhece as transformações funcionais. Ao contrário, debruça-se sobre elas traçando profunda análise, apenas sua vinculação dialética o leva à formulação das instituições jurídicas como modelos jurídicos fechados e estáticos, situando as transformações e evoluções fora do âmbito jurídico.

As estruturas sociais, as instituições jurídicas como estruturas fundamentais na concepção de Reale, integram os modelos jurídicos que representam toda uma estrutura normativa que ordena fatos segundo valores.

O que para Renner é metajurídico e ajurídico está integrado na concepção de modelo Realeana.

A compreensão de modelo em Reale não vem, de outro lado, estabelecer confusão no que se refere à definição do campo da filosofia e da sociologia do direito.

O jurista olha mais a norma, mas para compreendê-la em sua plenitude não pode deixar de recorrer a fatos e valores.

A perspectiva dominante do valor é matéria da filosofia do direito.

A prevalência do elemento fático é determinante para a sociologia do direito, e o horizonte do jurista é marcado por um sistema de normas legais, mas os três elementos são indispensáveis para uma compreensão adequada do direito.

\section{Conclusão}

Conclui-se que as instituiçōes jurídicas ou as estruturas fundamentais do direito 
podem ser vistas, também, como modelos jurídicos.

No tocante à estrutura científica do direito sobre a qual Renner desenvolve seu trabalho ao examinar instituições jurídicas do direito privado com ênfase na instituição da propriedade e instituições jurídicas complementares, detendo-se no estudo da função social exercida por estas instituições, encontra-se como ponto-chave sua concepção de instituições jurídicas - como estáticas e estáveis, e a dinâmica das profundas alterações da função social destas instituiçōes como matéria fora do âmbito jurídico. Já a concepção de Miguel Reale de modelo jurídico compreende a dinâmica da norma enquanto se atualiza na dialética de implicação e polaridade de fato, valor e norma e apresenta-se, não só contemporânea, como compatível com a noção de instituições jurídicas tal como foram identificadas pelos romanos e como modernamente são empregadas, isto é, de instituições, modelos ou estruturas jurídicas fundamentais essencialmente dinâmicas.

Diferem fundamentalmente os autores pela própria concepção de instituição e modelo jurídico com que trabalham.

Renner, que adota o modelo jurídico fechado e vinculado ao pensamento marxista e positivista, concebe a função social como fora do âmbito do direito

Reale concebe os modelos jurídicos abertos e dinâmicos abrangendo em si próprios as alteraçoes do direito enquanto se atualiza.

As profundas mudanças havidas neste século conduzem à necessidade de uma compreensão da experiência jurídica, não só como dinâmica, mas também como autora de mudanças sociais, identificando-se, claramente, as interinfluências de instituiçōes ou modelos e suas fases de formação, formulação como norma e pela função social exercida pela norma em constante interação.

Notas

1 O pensamento jurídico-filosófico de Miguel Reale está contido em cerca de 30 obras publicadas, das quais se destacam sua Filosofia do Direito (com publicação Iniciada em 1953), a obra Direito como Experiência (1968), a Teoria Tridimensional do Direito (1968), a Teoria do Direito e do Estado (1940) e Lisốes Preliminara

2 Coelho, Luiz Fernando - Dialética e modelo em Reale. Revista Brasileira de Filosofia. São Paulo, oㅡ 132, p.397-423, out./nov./dez., 1983.

${ }^{3}$ Carbonier, Jean - Sociologia jurídica. Coimbra, Livraria Almedina, 1979, pp.108-111.

${ }^{4}$ Renner, Karl - The institutions of privale lawe and their social functions. London: International Library of Sociology and Social Reconstruction, Karl Manheim, $1^{\underline{1}}$ public., 1949. Introdução e notas de O. Kahn Freund, p.1.

5 Miguel Reale nasceu em 1910, no Estado de São Paulo, filósofo, jurista, catedrático de Filosofia do Direito na USP e antigo reitor dessa Universidade, fundador do Instituto Brasileiro de Filosofia e Diretor da Revista Brasileira de Filosofia, exercendo também a coordenação da Comissão Revisora e Elaboradora do projeto de Código Civil.

Reale, Miguel. O direito como experiência. São Paulo, Saraiva, 1968. O autor já havia apresentado uma comunicacão denominada "Para uma teoria dos modelos jurídicos" no Congresso Internacional de Filosofia, em Viena, em 1968, desenvolvendo a matéria significativamente na obra "O direito como experiência", do mesmo ano.

Reale, Miguel, op.cit. na nota 6, pp.42-43.

8 Reale, Miguel, op.cit. na nota 6, p.43.

9 Id.ibid. p. 45. O próprio Reale menciona pesquisas anteriores como as de Enrico de Robilant mesmo tendo realizado seus estudos sem delas se valer, uma vez que coincidiram com suas investigações. Menciona igualmente que pesquisas e indagaçōes vinham sendo ealizadas sobre "estruturas sociais" por Talcott Parsons Robert K. Merton, e igualmente destaca o relevo adquirido pela teoria dos modelos nos diversos domínios da epistemologia ou teoria das ciências, como se pode observar em Reale, Miguel - Nova fase do direito moderno, São Paulo, Saraiva, 1990, p.163.

${ }^{0}$ Tem-se aí um processo de contínua regeneração e realimentação, de autocorreção face às mutações que ocorrem no plano dos fatos, dos valores e das próprias normas, como se pode ver na obra citada na nota anterior, p. 165 .

${ }^{11}$ Aqui as diversas concep̧ões jusfilosóficas apontam para soluçōes diferenciadas que vão do estrito apego à norma estabelecida à atuação criadora do intérprete e do julgador.

12 Coelho, Luiz Fernando - Dialética e modelo em Reale. Revista Brasileira de Filosofia. São Paulo, nº132,

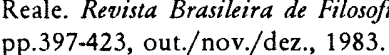

pp.397-423, out./nov./dez., 1983.
13 Reale, Miguel, op.cit. na nota 6, p.161.

14 Id. ibid., p.162.
15 Reale, Miguel. Teoria tridimensional do direito. São Paulo, Saraiva, 1986, p.11.

16 Reale, Miguel. Direito natural, direito positivo. São Paulo, Saraiva, 1984, p.47.

17 Id.Ibid., pp.47 e 48.

${ }^{18}$ A visão de Reale, sua dialética aberta representa uma oposição ao positivismo de um lado e ao neotomismo

19 Id.Ibid., p.42.

${ }^{20}$ Reale, Miguel, op.cit: na nota 16, p.42.

21 Id.Ibid., p.50.

22 Id.ibid., p. 51

${ }^{23}$ Id.Ibid., p.5

24 Reale, Miguel, op.cit. na nota 16, p.56.

25 Karl Renner viveu de 1870 a 1950 . Foi presidente da República da Austria logo após a $2^{\mathrm{a}}$ Guerra Mundial, Carbonier, Jean, op.cit., pp.100-11

${ }^{26}$ Friedmann, W. Legal theory. London, Stevens e Sons, 1960, pp.496 e segs.

27 Ao pressupor as instituiçōes jurídicas como estáticas, Renner, de certa forma, não adere integralmente à tese marxista que atribui à infra-estrura o fator determinante e que suas mudanças refletem-se obrigatoriasuperestrutura.

${ }^{28}$ Afirma o autor que as instituiçōes legais são neutras, não interessando ao direito a utilização dada pelo particular às mesmas, situando-se os efeitos econôm cos e sociais fora do campo do direito

${ }^{29}$ Renner, Karl, op.cit. p.255, e que O. Kahn-Freund ressalta em sua introdução, p.4.

${ }^{30}$ Neste ponto, Renner concorda com Savigny e Maine da escola histórica, todavia por diferentes motivos e fundamentos, como bem observa O. Kahn Freund em sua introdução à obra de Renner, p.4.

31 Renner, Karl, op.cit., introdução de O. KahnFreund, p. 4 e texto do autor, pp. 258 a 260

32 Renner, Karl, op.cit,, ver Introdução de O. Kahn -Freund, p.6.

${ }^{33} \mathrm{~A}$ concepção da norma como estática hoje não passa de uma fiç̧ão.

34 Renner, Karl, op.cit., p.71 e Introduçāo de O. Kahn-Freund, p.6.

35 Id.Ibib., p. 6.

${ }^{36}$ Renner, Karl, op.cit., p.73 e Introdução de O. Kahn-Freund, p.6.

37 Não se pode deixar de ter presente a época em que foi escrito o trabalho de Renner, quando ainda er cio do direito privado de propriedade, hoje indissoci vel da obrigacos negativas e positivas decorrentes do conteúdo social que delineia o exercicio deste direito.

38 Ver sobre este aspecto os comentaios de $O$. Kahn38 Ver sobre este aspecto os comentarios de O. Kah -Freund à obra de Karl Renner, op.cit. pp.17-18.
39 Renner, Karl, op.cit, Introdução de O. KahnFreund, p.25.

$40 \mathrm{Na}$ verdade, não houve apenas mudança da função social da propriedade, houve, isto sim, uma redefinição de propriedade de acordo com a concep̧ão romana ou seja, não mais a propriedade de domínio senhorial dos senhores feudais, que não a exploravam diretamente, à qual se sobrepunha a posse dos vassalos que incluia o uso, desfrute e direito de transmissão aos seus herdeiros, todavia, profundamente vinculadas aos senhorios.

${ }^{41}$ Ver análise de O. Kahn-Freund ao trabalho de Renner cit pp. 25-26.

42 A constituição de hipotecas especialmente na produção da habitação no meio urbano, o arrendamento rural da propriedade agrícola podem reduzir a proprie dade a uma ficção.

43 Ver Friedmann, W. Legal tbeory. London, Stevens e Sons, 1960, p. 330 .

44 Id.Ibid., p. 330.

45 Id.Ibid., p. 330 .

$46 \mathrm{O}$ mecanismo do capital tornou-se tão refinado que a propriedade corpórea cessou de ser ingrediente essen-

${ }^{47}$ Valor inestimável para a vivência jurídica foi efetivamente o fato realizado pelos romanos de extrair identificar de uma multiplicidade de normas as instituiçôes juridicas como estruturas fundamentais do didireito romano e sua história, atestam isto.

48 Renner, Karl, op.cit., Introdução de O. kahnFreund, p.11.

${ }^{49}$ Ver sobre o positivismo científico as lições de Wieacker, pp.491 e segs.

${ }^{50}$ Não se pode perder de vista a época da formulação do trabalho de Renner, no auge da codificação, sendo então, compreensível seu apego à estabilidade e imutabilidade das normas.

51 Renner, Karl, op.cit., Introduçăo de O. Kahan-Freund, p.2.

52 Renner, Karl, op.cit., p.53 Every legal institution is to a conceptual approach a composit of norms, a total of imperatives.

53 Renner, Karl, op.cit., Introdução de O. KahnFreund, p.3. "The functional transformation of legal insttutions wich Renner examines in bis work is not - be tutions zoich Renner examines in bis work is not - be emphasises "to again and again - a transformation

54 Ver Wieacker, Franz. História do direito privado moderno. Lisboa, Fundação Calouste-Gulbenkian, 1980. pp.518 a 521. No ponto de vista de Gierke, todo a nocial era potencialmente direito, constferia direito uma teoria social; para Renner o direito se reduz à norma, seus efeitos e funçōes se realizam fora do direito.

55 Ver Renner, Karl, op.cit., pp. 55 e 56 
$56 \mathrm{O}$ autor expressamente exclui como ajurídicos os elementos metajurídicos em coerência com seu pensamento positivista-marxista.

57 Renner, Karl, op.cit., p.252 "Howe does this change of functions come about? We bave seen that it proceeds steadily, continously, imperceptibly, like the growtb of grass, according to the law of all organic development. As the process of gronetb cannot be understood by a glance at the plant, but only by study of the zerole successive development from germ 10 fruil and again to the nere germ; so the change of furcent "ben only zeben it bas matured".

\section{Bibliografia}

Carbonier, Jean. Sociologia jurídica, Coimbra: Almedina, 1979.

Coelho, Luiz Fernando. Dialética e modelo em Reale. Revista Brasileira de Filosofia São Paulo: nº 132, pp. 397-423, out./nov./dez. 1983.

Czerna, Renato Cizell. A dialética de implicaçăo e polaridade do criticismo ontognoseológico. Revista Brasileira de Filosofia. São Paulo: no 42, pp.243-255, abr./mai./jun. 1961.

Dujovne, Leon - La filosofía del derecho de Hegel a Kelsen, Buenos Aires, Bibliografica Argentina, 1963.

Ferraz Jr., Tércio Sampaio. Algumas observaçōes em torno da cientificidade do direito segundo Migu Reale. Revista Brasileira de Filosofia. São Paulo: $\mathrm{n}^{\circ} 74$, pp. 220-240, abr./mai./jun. 1969

Ferreira, Pinto. O pensamento jurídico-filosófico de Miguel Reale. Revista Brasileira de Filosofia. São Paulo: $\mathrm{n}^{\mathrm{o}} 140$, pp.386-493, out/nov/dez. 1985. riedmann. W. - Legal theory. Stevens e Sons, London, 1960.

Legaz y Lacambra, Luis. Dos libros del professor Miguel Reale. Revisla Brasileira de Filosofia. São Paulo: no 81, pp. 3-8, jan./fev./mar. 1971.

Llorente, Francisco Olmedo. La dialectica de complementariedad en Miguel Reale. Revista Brasileira de Filosofia. São Paulo: $\mathrm{n}^{2} 113$, pp. $27-38$, jan./fev./mar. 1979.

Miguel Reale na UnB: (Conferência e debates de seminário realizado de 9 a 12 de junho de 1981). Brasília: Editora Universidade de Brasilia, 1981.

Reale, Miguel. $O$ direito como experiência. São Paulo: Saraiva, 1968.

Reale, Miguel. Teoria tridimensional do direito. São Pau. lo: Saraiva, 1968

Reale, Miguel. Direito natural/direito positivo. São Paulo: Saraiva, 1984.

Reale, Miguel. Liģốs preliminares de direito. São Paulo Saraiva, 1990.

Reale, Miguel. Teoria do direito e do estado. São Paulo: Saraiva, 1984.

Reale, Miguel. Filosofia do direito. São Paulo: Saraiva, 1990.

Renner. The institutions of private law and tbeir social functions. London: International Library of Sociology and Social Reconstruction, Karl Mannheim, 1949

Strenger, Irineu. Contribuiçào de Miguel Reale à teoria do direito e do estado. Revista Brasileira de Filosofia. São Paulo: no 42, pp. 234-247, abr./mai./jun. 1961.

ieacker, Franz. História do direito privado moderno, Lisboa: Fundação Calouste-Gulbenkian, 1980.

\section{As cartas de intenção no processo formativo da contratação internacional: os graus de eficácia dos contratos e a responsabilidade pré-negocial}

Trabalho apresentado no seminário sobre "Contratos Internacionais e Mercosul", .

Judith Martins-Costa

Professora de Direito Civil na Faculdade de Direito da UFRGS.

SUMÁRIO

Introdução. I) As Condições Necessárias ao Estabelecimento de Vinculação Jurídica Negocial e Pré-Negocial: a) As Categorias Jurídicas da Proposta e da Aceitaçāo; b) A Relação Jurídica Estabelecida Mediante a Troca de Cartas ge Intenção: II) Os Efeitos Decorrentes da Vinculacão Estabelecida Mediante a Troca de "Cartas de intenção" a) Cartas de Intenção e Efićácia de Primeiro Grau; b) A Configuração da Responsabilidade Pré-Negocial pela Ruptura Injustificada das Tratativas. Conclusão.

\section{Abstract}

Les relations internationales génèrent, actuellement, l'expansion de types et de formes de liens intersubjectifs assez divers par rapport à ceux qui, d'une façon traditionnelle, on désigne "contrat". Aux contrats internationaux précède, ba bituellement, une période pré-contractuelle où les futurs contractants échangent des documents et se donnent des lettres où sont établis certains points d'accord qui devront être postérieurement ratifiés. Pour les contrats internationaux on ut lise, dans cette phase pré-contractuelle, certaines figures juridiques, entre autres les "lettres d'intention", documents destinés à fixer les bases contractuelles avant l'établissement du conten contractuel intégral. La question qui se pose est donc, de déterminer si les "lettres d'intention" générent - et, si génerent, sous quel fondément des liens juriques d'obligation entre les parties, vue la distinction entre ces lettres et le pré-con trat. Cet étude se divise, ainsi, em deux parties. dans la première on analyse les conditions néces saires à l'etablissement des liens juridiques con tractuels; dans la deuxiéme, en s'appuyant sur le droit comparé, on examine les effects $d u$ lien établi travers le changement de lettres d'intention.
Introdução

Quem observar o que ocorre atualmente na prática do comercio internacional perceberá a expansão de tipos e formas vincula tivas em tudo e por tudo diversas daqueles que poderiam ser agrupados sob o conceito tradicional de contrato - tal como advindo este, do modelo posto pela Codificação do século XIX - ao ponto de a doutrina apontar à visualização de uma nova lex mercatoria ${ }^{1}$ a conformar regras e a criar modelos jurídicos à margem do direito posto pelo Estado.

Por estas razões, o exame dos contratos internacionais não pode restar reduzido como quer certa doutrina, apenas aos pontos tradicionalmente demarcados pela disciplina do Direito Internacional Privado, vale dizer, a sua relação à determinada ordem jurídica estatal ou interestatal ou ao critério meramente formal ou externo da internacionalidade. Isto porque, no quadro atualmente delineado, os contratos internacionais não se alocam apenas como relações de intercâmbio fundamentadas numa determinada noção de contrato que não é mais do que a de um contrato comum afetado pelo problema da estraneidade - exame para qual bastaria determinar qual a lei aplicável 